\title{
Proposals to Promote the Development of Virtual Reality in China-Based on Patent Econometric Analysis
}

\author{
Zhengang Zhang, Minglun Xu, Jieming Huang \\ School of Business Administration, South China University of Technology, Guangzhou, China \\ Email:283327513@qq.com
}

How to cite this paper: Zhang, Z.G., Xu, M.L. and Huang, J.M. (2018) Proposals to Promote the Development of Virtual Reality in China-Based on Patent Econometric Analysis. Engineering, 10, 291-304. https://doi.org/10.4236/eng.2018.105020

Received: February 28, 2018

Accepted: May 22, 2018

Published: May 25, 2018

Copyright (c) 2018 by authors and Scientific Research Publishing Inc. This work is licensed under the Creative Commons Attribution International License (CC BY 4.0).

http://creativecommons.org/licenses/by/4.0/

\section{(c) (i) Open Access}

\begin{abstract}
Virtual reality technology has great potential for development and application space. On the one hand, this paper makes use of the data of Derwent Patent Database to carry out statistical analysis of the information, and analyzes the basic situation of the patent of virtual reality technology. On the other hand, this paper uses the Citespace software to analyze and process the retrieval records, and then obtains the relation of intermediary center, frequency of occurrence, burst term and other related data. According to these data, it analyzes and forecasts the core technologies, cutting-edge and hot technologies of virtual reality, which makes the future development of virtual reality technology more clear. At the same time, combined with the current development of virtual reality, this paper makes recommendations for the future development of China's virtual reality technology to promote the development of virtual reality industry in China.
\end{abstract}

\section{Keywords}

Virtual Reality Technology, Patent Analysis, Cutting-Edge and Hot

Technologies

\section{Introduction}

In the 1980s, Jaron Lanier, the founder of VPL Research Company of the United States, put forward the Virtual Reality (VR) for the first time [1]. After that, with the rapid of development of computer technology, virtual reality gained a good basis whether in hardware or software. The development of its technology becomes more and more mature, and its applications become more and more extensive. Since Oculus and other virtual reality teams significantly breakthrough 
VR technologies, a new round of VR craze has been set off globally. Once again, Virtual Reality has become one of the hot topics. In 2014, the move that Facebook acquired Oculus for $\$ 2$ billion and the continuous improvement of VR technology have made the public increasingly look forward to the fantastic future of virtual reality.

Virtual Reality, in simple terms, means giving users an immersive experience with hardware such as head-mounted devices and specially crafted virtual reality content. It has three important features (often called 3I features), namely Imagination, Interactivity and Immersion [2] [3], all of which emphasize people's leading role in the virtual system. In other words, human feelings are most important in the virtual reality system. As early as the 1980s, virtual reality has been applied to national defense, military and aerospace and other state-level plans. With the gradual development of virtual reality technology, virtual reality has gradually entered all aspects of people's lives [4]. Among them, virtual reality is mostly applied in the field of games, and then gradually extends to other fields of application such as real estate, healthcare, live events, educational training and so on. All countries have introduced relevant policies one after another. In addition to focusing on the virtual reality industry, these policies point out that they should not only strengthen the application of virtual reality in medical, cultural and entertainment fields, but also achieve technological breakthroughs in the fields of image, interaction and data transmission [5]. However, related technologies in the field of virtual reality, such as near-eye display, technologies of perceptual interaction, communication and transmission, content production and so on, are not yet mature. Currently, they are still in the stage of tackling key technical problems and restricting the development of virtual reality industry [6]. Virtual reality is regarded as one of the most potential development disciplines in the 21st century which has become one of the focuses of global attention. Therefore, capturing the key core technologies of virtual reality is particularly crucial for promoting the development of the virtual reality industry. Our research analyzes the patent of virtual reality technology, and then analyzes the development and layout of global virtual reality technology. Furthermore, we identify the key, hot and cutting-edge virtual reality technology to predict the future development trend of virtual reality, so as to guide the technological development and strategic layout of virtual reality in China more accurately, which can help us seize the high ground of technology.

\section{Data Sources and Analytical Methods}

\subsection{Data Sources}

The data of our study are based on the Derwent Innovations Index (DII). DII is developed in collaboration with the Derwent Company and the Institute for Scientific Information (ISI), which integrates the Derwent World Patent Index (WPI) with the Patent Citation Index (PCI). Currently, including over 40 patent 
agencies, 10 million basic invention patents and 30 million patents worldwide, DII now is one of the most comprehensive databases in the world for international patent information [7]. Based on more than 5000 rules, hundreds of professionally trained experts in various fields standardize, standardize and correct over 6000 pieces of data in the database weekly, which makes the data highly authoritative and reliable.

In the existing literature on patent analysis of virtual reality technology, except for the keywords, most of retrieval formulas contain Derwent manual code that is proprietary to the virtual reality technology, which makes the final result difficult to guarantee the validity of future predictions. Therefore, our study uses $\mathrm{TS}=$ ("virtual reality" or "VR" or "virtual reality technology" or "virtual reality technique ${ }^{\star "}$ or "virtual reality system*" or "VR system*") as search formula. And then we downloaded 24,703 technical patents related to the topic of virtual reality from the year 1994 to the download date on September 15, 2017. Each patent covers the title of the patent, the patent number, the patentee, Derwent manual code, abstract and other information which are used for later analysis.

\subsection{Analytical Methods}

The existing literature mainly analyzes the surface information of virtual reality technology patents, such as patentee, Derwent manual code, patent distribution, etc. However, patent information has not been analyzed in depth and the future trend of the virtual reality industry has not yet been predicted. In other fields, some scholars have conducted in-depth studies. Morar, Agachi (2010) [8] and others used CiteSpace software to conduct in-depth research on the development and emerging trends of thermal integration and heat exchanger network systems. Huang Lucheng, Wang Kai, et al. (2014) [9] used the word frequency detection technology provided by CiteSpace to analyze the patent of the home air conditioners and then to draw a knowledge map of the hotspot and cutting-edge technologies of home air conditioners. According to the knowledge map, they analyzed the development trend.

Therefore, our study analyzes the patent of virtual reality technology in two aspects. On the one hand, our study makes use of the application number, patent number, patentee and other data and information statistics of virtual reality technology patent that are retrieved from Derwent Patent Database, so that we can analyzes the basic situation of virtual reality technology patents. On the other hand, our study mainly analyzes Derwent manual code of the 24,703 records retrieved by Citespace software, and then draws relevant maps such as co-word and time-zone views as well as related data like centrality, frequency of occurrence, sudden occurrence, etc. After that, we analyze and predict the core technologies, hot technologies and cutting-edge technologies of the virtual reality industry so as to make the future direction of technology development in the virtual reality field clearer. 


\section{Basic Situation of Virtual Reality Patent Distribution}

\subsection{General Trend Analysis of Patent Applications}

From the perspective of the development trend of global virtual reality patent (as shown in Figure 1), since 1994, the number of virtual reality patent applications has generally been the upward trend overall. Especially after VR technologies being broken by some innovation teams of virtual reality such as Oculus in 2012, a new round of VR craze has been set off worldwide, and the number of patent applications for virtual reality technology has an explosive growth. It's easy to find that the number of applications in 2016 is nearly double that of 2015. In view of this, global virtual reality technology research and development heat is increasing and entering a period of rapid development. Virtual reality has gradually become one of the world's focuses.

\subsection{Global Layout}

From the perspective of the global layout of virtual reality patents (as shown in Figure 2), the patents of virtual reality technology are mainly concentrated in five major countries or regions, namely the United States, China, Japan, South Korea and the European Patent Office. The total number of U.S. virtual reality technology patent applications was as high as 10,295, ranking the first place. Ranked second in China and the third in Japan are two times as many as the total number of applications in South Korea and the EU, which shows that the research and development strength of virtual reality technology is dominated by the United States, Japan, and China.

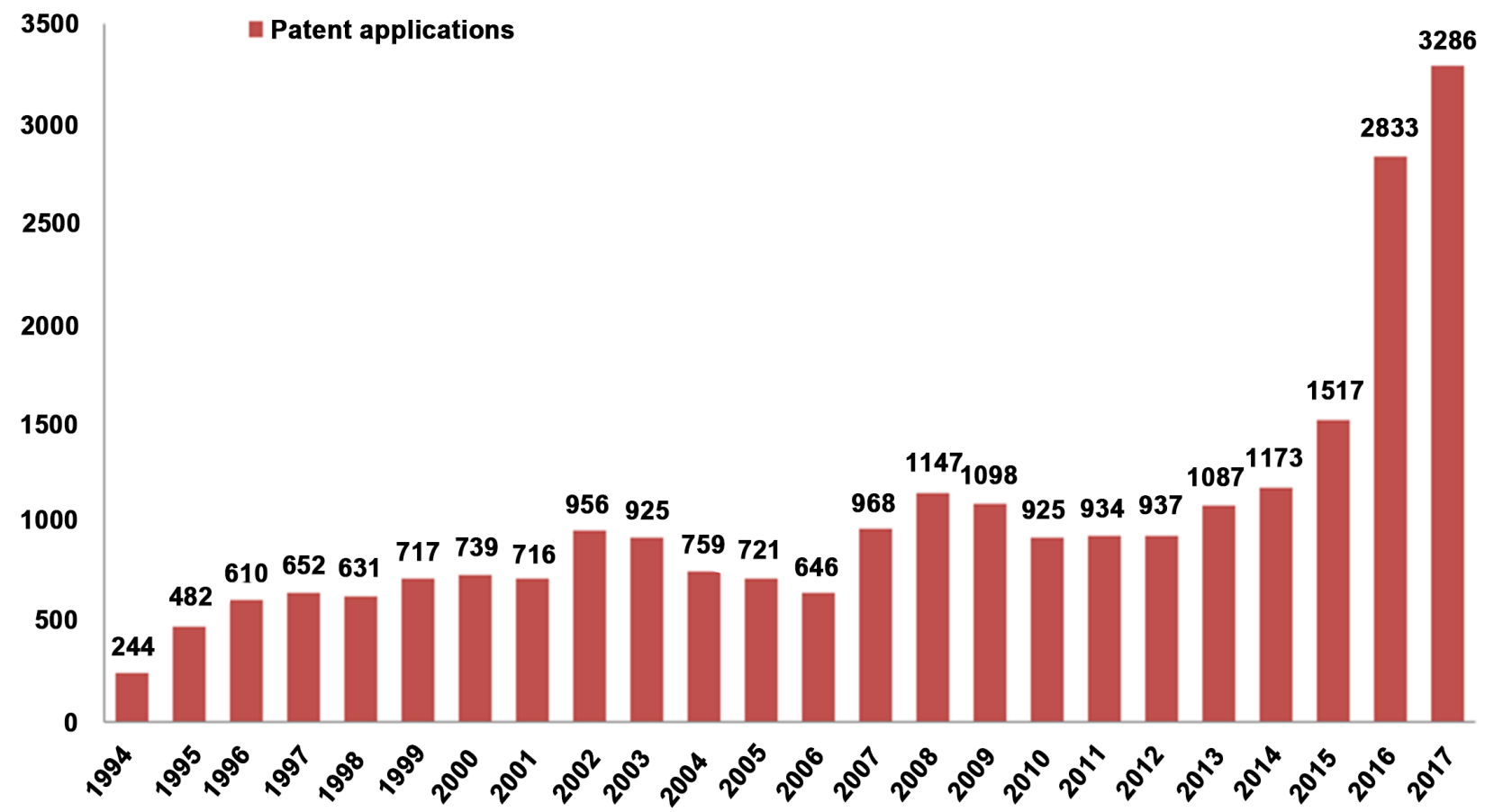

Figure 1. Application trend of virtual reality patent (1994-2017). 


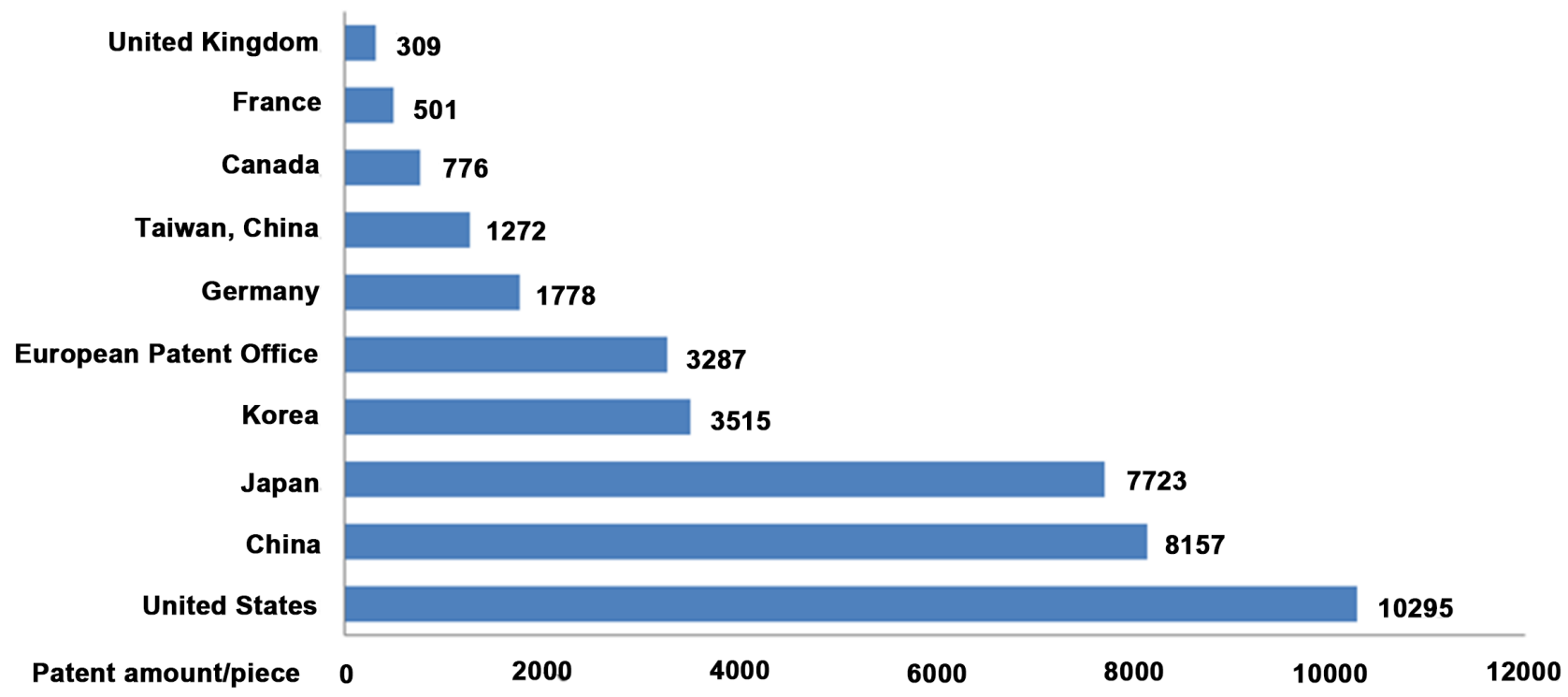

Figure 2. Application area analysis of virtual reality patent (1994-2017).

From the perspective of the trends of patent applications in major countries (as shown in Figure 3), before 2006, the United States and Japan were leaders in virtual reality technology and their $\mathrm{R} \& \mathrm{D}$ capabilities were almost equal. The development in South Korea and Europe was more synchronized and their pace was moderate. In China, the development of virtual reality technology started late. From 1994 to 2006, the total number of patent applications was only 750, less than $20 \%$ of that of the United States in the same period. Its research and development strength far outweighed that of the United States and Japan and lagged behind that of South Korea and the EU. After 2006, the U.S. virtual reality technology was still growing in a good and stable manner with strong research and development capabilities. However, the number of patents in Japan has been gradually declining. Both Korea and Europe maintained a steady pace of development. In China, The pace of virtual reality technology has gradually accelerated. By 2014, it even achieved a blowout growth. Since then, the number of annual patent applications of surpassed that of other countries. China has become the country with the most rapid development of virtual reality technology. Obviously, its research and development strength is constantly increasing.

\subsection{Patentee}

According to the top ten patentees of virtual reality technology applications (as shown in Table 1), we can summarize the following three major characteristics. First of all, virtual reality has been valued by enterprises. Enterprises become the leading force for innovation. It's not difficult to find that the top ten patent applications are all enterprises. We can learn that on the one hand, the virtual reality technology has a high industrial value and is highly valued by enterprises. On the other hand, enterprises have now become the dominant force in the innovation and development of virtual reality technology. Secondly, Japan's research 


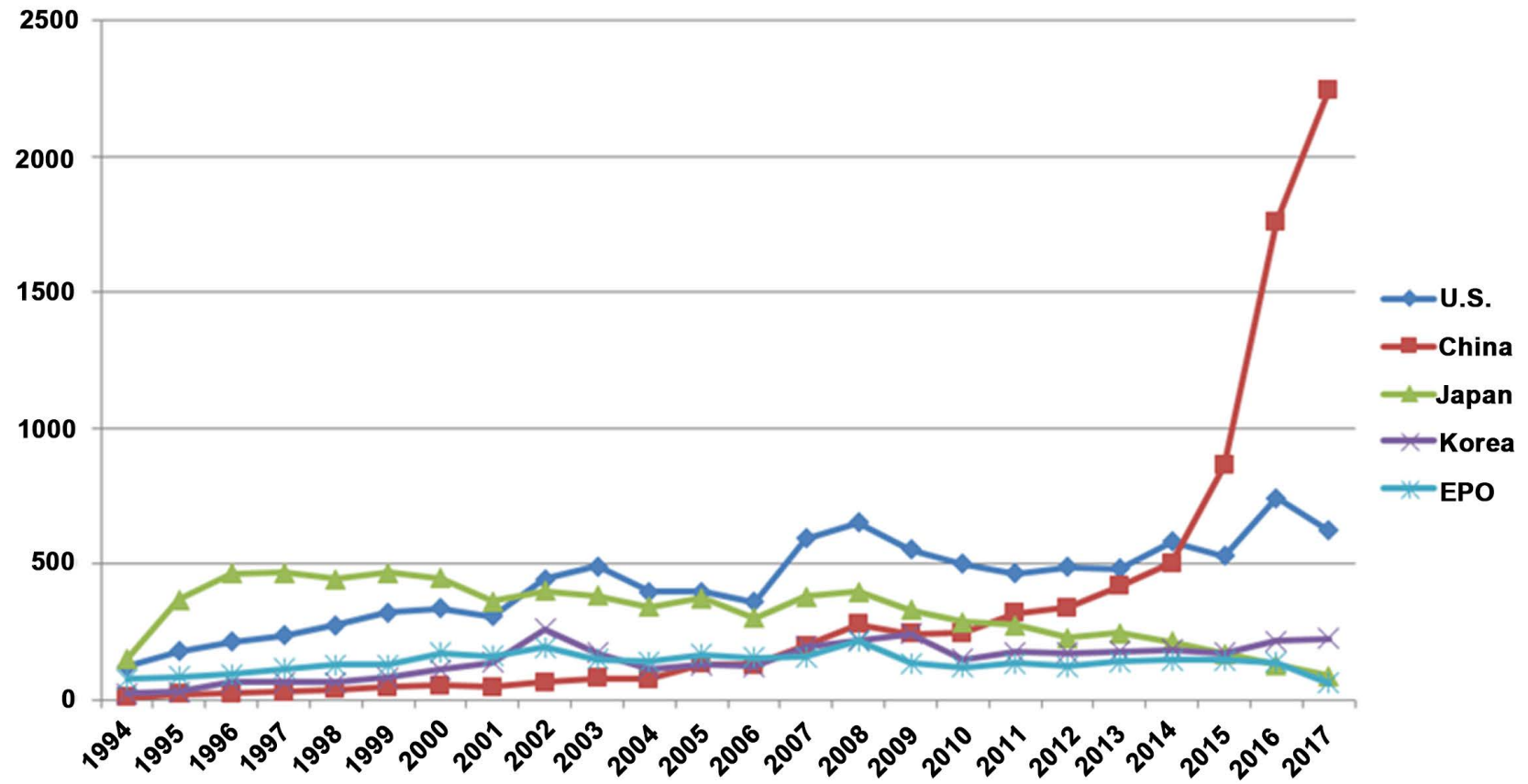

Figure 3. Patent application trends in major countries (1994-2017).

Table 1. Top ten patentees of virtual reality technology applications (1994-2017).

\begin{tabular}{cccc}
\hline No. & Name of Patentee & Number of Patents(pieces) & Own country(region) \\
\hline 1 & SAMSUNG ELECTRONICS CO LTD & 480 & Korea \\
2 & TOSHIBA KK & 405 & Japan \\
3 & SONY CORP & 339 & Japan \\
4 & HYNIX SEMICONDUCTOR INC & 302 & Korea \\
5 & MICRON TECHNOLOGY INC & 203 & United States \\
6 & NEC CORP & 202 & Japan \\
7 & MATSUSHITA DENKI SANGYO KK & 199 & United States \\
9 & INT BUSINESS MACHINES CORP & 198 & Japan \\
10 & CANON KK & 188 & 187 \\
\hline
\end{tabular}

and development capabilities are very strong, closely followed by Korea's and the United States'. Six of the top ten patentees come from Japan, including TOSHIBA KK, SONY CORP, NEC CORP, MATSUSHITA DENKI SANGYO KK, Canon CANON KK and FUJITSU LTD, two from Korea, namely SAMSUNG ELECTRONICS CO LTD and HYNIX SEMICONDUCTOR INC, two from the United States, namely MICRON TECHNOLOGY INC and IBM. Thirdly, the development of China's virtual reality technology is not yet mature, and there is still a gap compared with the international technology giants. None of the top 10 patentees belongs to China. However, the total number of virtual reality patent applications over the years in China has surpassed Japan, ranking 
second place. It shows that the overall strength of China's virtual reality enterprises still can't be comparable with the United States, Japan and South Korea. The enterprises of virtual reality field are still fledgling in the international community. Yet, enterprises, universities, research and development institutions of virtual reality technology studying in China have mushroomed appear. The development of virtual reality is worth the wait.

\section{The Core Technologies, Frontier and Hot Technologies Analysis}

In this paper, we use CiteSpace-V software to analyze and visualize 24,703 records of virtual reality, and then analyze the core technologies, hot and cutting-edge technologies in the field of virtual reality. Before analysis, the following parameters must be set in CiteSpace.

Time limit: 1994-2017, count once a year;

Keyword source: Title; Abstract; Author Keywords; Keywords Plus;

Node type: Category';

Selection criteria: Select 30 nodes with the highest frequency of occurrences each year.

Through software analyzing and proper revising, the virtual reality technology patent co-word network map is obtained (as shown in Figure 4). Each node in the graph represents a category of technology (in Derwent manual code). The larger the perimeter of each node means that the more number of patents associated with it during the analysis period. It can be found that in the co-word network map, the most frequently occurring patents in the past two decades are the virtual reality systems (T01-J40), video (W04-W07E1), required software products (T01-S03).

\subsection{Core Technology Analysis}

Core technology refers to the technology that plays the most crucial role in market competition in one industry [10]. In the co-word network, it is generally used the index named Betweeness Centrality to measure the importance of a node in the network [11]. The stronger the centrality, the more information flows of the patent represented by the node. It means that the patent is of great importance, and that will be the core one that we want. Therefore, we use the Betweeness Centrality to filter out the core technologies in the field of virtual reality, as shown in Table 2 .

As can be seen from Table 2, firstly, the highest centrality of virtual reality technology in recent 20 years is video game and other related technologies (W04-X02C), which indicates that the technology related to video games is the core technology in the virtual reality industry. Virtual reality is the best in the field of video games, and its technology is also very mature. Secondly, in the top 10 technologies with the highest centralization, the most common one belongs

${ }^{1}$ Select this one and draw related statistics of Derwent manual code. 


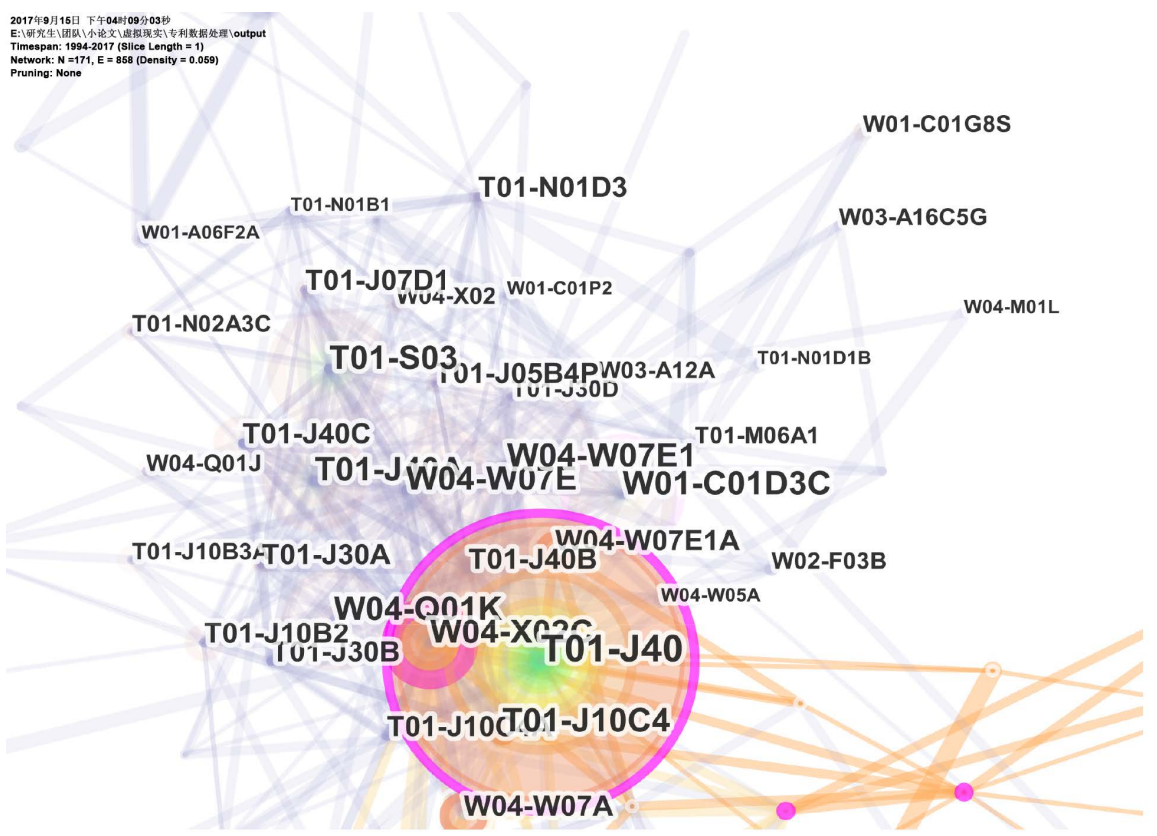

Figure 4. Co-word network map of global virtual reality (1994-2017).

Table-2. Betweeness centrality of virtual reality technology types (1994-2017).

\begin{tabular}{cccc}
\hline \multirow{2}{*}{ No. } & \multicolumn{2}{c}{ Technology Types } & \multirow{2}{*}{ Betweeness Centrality } \\
\cline { 2 - 3 } & Derwent manual code & Meaning & 0.21 \\
2 & W04-X02C & Video games & 0.14 \\
3 & T01-J40 & Virtual reality system & 0.12 \\
4 & W01-C01D3C & Portable; hand-held & 0.12 \\
5 & U24-G03L & Measures to improve stability & 0.11 \\
6 & T01-J10C5 & Store modeling data, animation & 0.11 \\
7 & T01-J10A2 & and graphics packages & 0.07 \\
8 & U14-A07 & Image memory management & 0.06 \\
9 & W04-W07E1 & Reading/writing & 0.06 \\
10 & T01-S03 & Video aspect & 0.05 \\
\hline
\end{tabular}

to the digital computer (T01), including five technologies. Among them, there are four attributable to the data processing system (T01-J), which means that data processing technology is one of the core technologies of virtual reality. Thirdly, the technology of portable handheld devices is also crucial to the development of virtual reality industry. Currently, most of the products related to virtual reality appear on the market in the form of hardware devices. Virtual reality application without devices still needs time to be achieved.

\subsection{Cutting-Edge and Hot Technology Identification}

Cutting-edge technology refers to the most advanced, the most worthwhile of 
study and has the potential for development of technology in the relevant fields [11]. At the same time, hot technology's time span should not be too long, otherwise it will easily lose its heat. CiteSpace software provides sudden strength, word frequency and other indicators to select the frontier and hot technology in some research field. Many scholars also use these indicators in various fields of hot and cutting-edge research. Chen Yue, Chen Chaomei et al. [11] used the indicator of Burst Strength to identify the frontier technology in a certain period of time, and pointed out that the nodes with high burst strength mean that these technical fields have particular attention between the burst time. To some extent, it shows that this area of technology is the forefront research in the period of time. Xiao Wan [12] and others use co-occurrence analysis of high-frequency keywords to reveal the frontiers and hot research in the field of hybrid learning. Teng Yalin [13] used the word frequency, the burst value and whether the burst period is close to the current period to determine the cutting-edge technology supply chain management research both here and abroad.

Therefore, based on the previous researches, our paper uses three indicators, namely burst strength, whether the burst period is close to the current period and the frequency of the manual code, to judge, identify and select the forefront and hot technologies of the virtual reality from 2007 to 2017. Using CiteSpace V software, we can draw a co-word network map of virtual reality patents from 2007 to 2017 (as shown in Figure 5). We also can statistically analyze the top 10 virtual reality patents which occur frequently (as shown in Table 3), as well as the top 10 technologies with highest burst strength (as shown in Table 4). Among the three indicators, if the technology meets the two of these indicators, it will be called the relative frontier and hot area. We should focus in the future. If the technology meets all three indicators, it is called the absolute frontier and hot area. We should focus on the layout of the field in the future. We hope that through effectively identifying the frontier and hot technologies of virtual reality, which will be conducive to the deployment of virtual reality technologies by universities, enterprises and research and development institutions in our country and then to gain competitive advantage in our country in advance.

It can be seen from Figure 5, Table 3 and Table 4 that the forefront and hot technologies of virtual reality in the past decade are mainly the virtual reality system(T01-J40), video and games (W04-W07E1, T01-J40A, W04-X02C), handheld devices (W01-C01D3C), storage power (U14-A09), storage and forwarding switching (W01-A06G2), packet transmission (W01-A03B). In summary, the forefront and key technologies of virtual reality are mainly divided into four areas. First area is display technologies, such as head-up display. Second area is the perception of interactive technologies, such as barrier-free communication, location recognition, 3D camera. Third area is communication transmission technologies, such as storage and forwarding switching, packet transmission. Fourth area are content production technologies, such as high immersive interactive video production, video content. Its application areas mainly in 


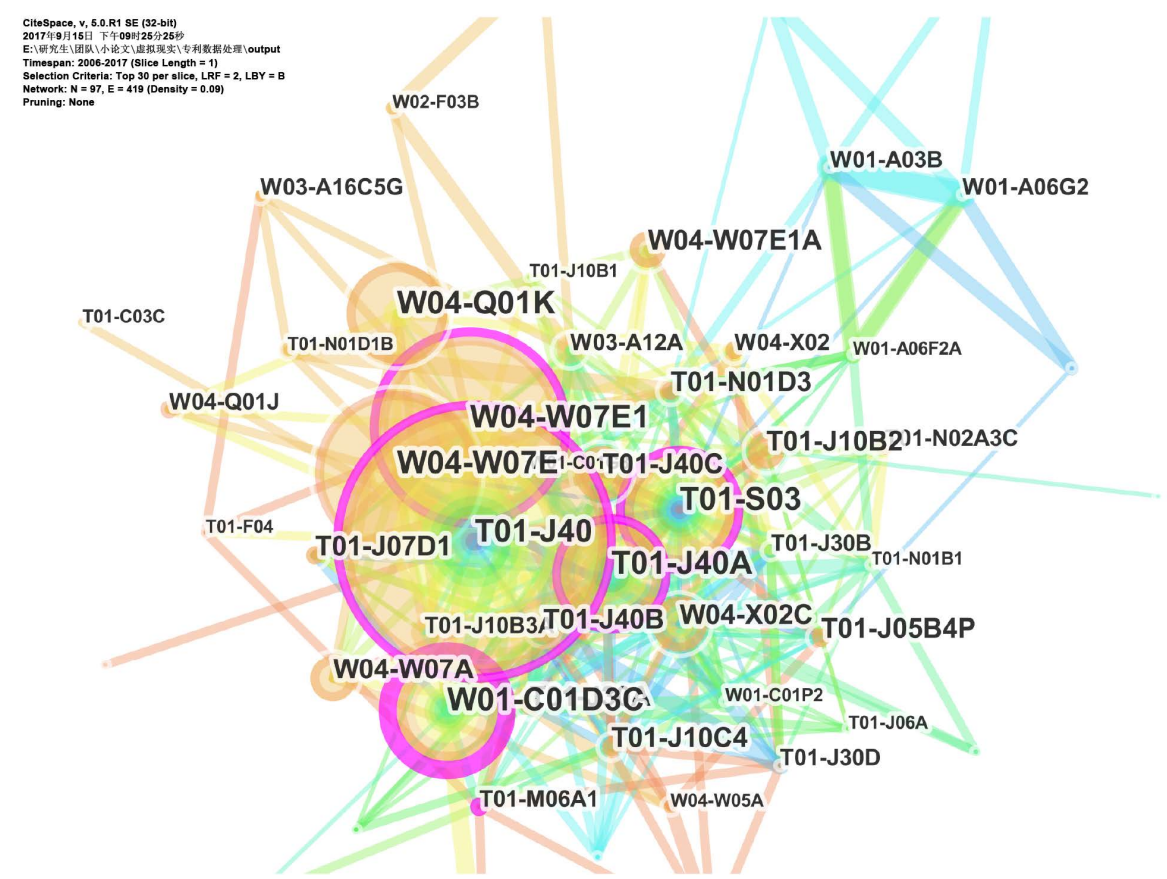

Figure 5. Co-word network map of global virtual reality (2007-2017).

Table 3. Top ten frequency of occurrence of virtual reality technology category (2007-2017).

\begin{tabular}{cccc}
\hline \multirow{2}{*}{ No. } & \multicolumn{2}{c}{ Technology Category } & $\begin{array}{c}\text { Frequency of } \\
\text { Occurrence }\end{array}$ \\
\cline { 2 - 3 } 1 & Derwent manual code & Meaning & 1723 \\
2 & T01-J40 & Virtual reality system & 1111 \\
3 & W04-W07E1 & Video aspect & 1052 \\
4 & W04-W07E & Virtual and augmented reality & 876 \\
5 & T01-S03 & Requires software product & 830 \\
6 & W01-C01D3C & Portable; hand-held & 785 \\
7 & T01-J40A & Game & 702 \\
8 & W04-Q01K & Head-up display application & 589 \\
9 & W04-X02C & Video games & 462 \\
10 & T01-J40B & Training/exercise aids & 456 \\
\hline
\end{tabular}

video, games, sports supporting. Equipment hardware are mainly in the research of virtual reality hardware system, location identification, storage power, low-power systems and portable handheld devices. Among them, the video (W04-W07E1) is not only frequent, but with high burst strength. Besides, its burst period is the closest to the current period, so it is the absolute frontiers and hot areas of the field of virtual reality. We should focus on the layout of the video field in the future. 
Table 4. Top ten burst strength of virtual reality technologies (2007-2017).

\begin{tabular}{|c|c|c|c|c|c|c|}
\hline \multirow{2}{*}{ No. } & \multicolumn{2}{|c|}{ Technology Category } & \multirow{2}{*}{$\begin{array}{c}\text { Burst } \\
\text { Strength }\end{array}$} & \multirow{2}{*}{ Beginning } & \multirow{2}{*}{ Ending } & \multirow{2}{*}{$\begin{array}{c}\text { Burst Period } \\
\text { Map(2007-2017) }\end{array}$} \\
\hline & Manual code & Meaning & & & & \\
\hline 1 & U14-A09 & Storage power & 50.43 & 2007 & 2011 & ---- \\
\hline 2 & $\mathrm{U} 24-\mathrm{H}$ & Low-power system & 108.91 & 2007 & 2012 & \\
\hline 3 & U24-G03L & $\begin{array}{l}\text { Measures to improve } \\
\text { stability }\end{array}$ & 50.81 & 2007 & 2013 & \\
\hline 4 & U14-A03B7 & $\begin{array}{l}\text { Memory with } \\
\text { adjustable threshold } \\
\text { MOS transistors }\end{array}$ & 39.12 & 2007 & 2014 & - \\
\hline 5 & W01-A06G2 & $\begin{array}{l}\text { Store and forward } \\
\text { switch }\end{array}$ & 61.64 & 2008 & 2013 & - \\
\hline 6 & W01-A03B & Packet transmission & 53.25 & 2008 & 2013 & - \\
\hline 7 & W01-C01P2 & $\begin{array}{l}\text { Personal digital } \\
\text { assistant }\end{array}$ & 45.07 & 2011 & 2013 & \\
\hline 8 & W01-A06F2A & Location recognition & 43.50 & 2011 & 2013 & 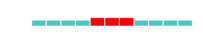 \\
\hline 9 & U24-D02A & $\begin{array}{c}\text { Barrier-free } \\
\text { communication }\end{array}$ & 40.08 & 2012 & 2014 & -1-men- \\
\hline 10 & W04-W07E1 & Video aspect & 112.29 & 2015 & 2017 & -_-_-_-_-_- \\
\hline
\end{tabular}

It can be found that the core technology of virtual reality in the past 20 years and the frontier and hot technology in the past 10 years are quite similar. This shows that the global virtual reality enterprise has realized the importance of the relevant core technology and gradually strengthened the research and development strength in that field, in order to gain the market competitiveness more quickly. In recent years, giants and hardware manufacturers such as Apple Inc., Microsoft, Twitter and other major Internet companies in the world have all stepped up the research and development of virtual reality technologies to increase the layout in the field of virtual reality. They are mainly distributed in the fields of video, games, movies and theme parks [14] [15]. China should also step up its pace of development, seize the opportunity of virtual reality development and speed up its layout in the frontier and hot areas.

\section{Research Conclusions \& Suggestions on the Development of Virtual Reality in China}

According to the above patent analysis, we found that the current technology related to video games is the core technology in the virtual reality industry. Besides, in video games, virtual reality has the best development and the most mature technologies. Data processing, portable handheld device technology is the core technology of virtual reality. Video, virtual reality systems, handheld devices, storage power are frontier and hot areas in the field of virtual reality. It is also an area where colleges and universities, research institutes and enterprises should lay stress on the layout in the future. With the introduction of Oculus Rift, HTC Vive and so on, the virtual reality industry will usher in a period of rapid development. Various forecasts show that the global VR market will burst 
with a large-scale in the next 3 to 10 years. China should seize the opportunity to speed up the layout of the field of virtual reality. In this regard, combined with the above conclusion and the current status of the development of virtual reality, our paper proposes three suggestions to promote the development of China's virtual reality technology and industry.

First of all, universities, research institutes and enterprises should be encouraged to strengthen the identification and screening of the core, cutting-edge and hot technologies in the field of virtual reality. Speeding up China's R \& D and industrial chain layout of virtual reality technology by increasing investment in scientific research, attracting professionals in related fields, absorbing and introducing advanced technologies from other countries such as Japan and the United States. Focusing on key technologies in software modeling, sensors, interactive technologies, computing chips and displays, and emphasizing the application of virtual reality technology in video and games, then accelerating the industrialization of related virtual reality products to promote the development of China's virtual reality industry.

Secondly, a talent cultivation mechanism should be established to encourage schools and enterprises to cultivate virtual reality professionals. Education in school is the foundation of the country, which can provide the virtual reality industry with a large enough base for personnel training, so that the educated people can have a solid foundation in professional knowledge and skills. This can also play a key role in finding an entry point for those who are willing to engage in the virtual reality industry. Functional departments, educators and professionals in this industry should strengthen communication with each other and reach consensus on the creation of virtual reality hot fields such as games and video and the cultivation of corresponding talents. In addition, relevant mechanisms should be set up by using continuing education of relevant virtual reality industry associations so as to achieve the upgrading of practitioners' skills and keep up with the pace of the virtual reality era. Companies should also take on the important task of personnel training and construct a vocational training system to create higher-level personnel.

Thirdly, the technical standard system should be established and improved to regulate the development of the industry. Since January 2016, the National Bureau of Standards and Technology has focused on planning standards for the virtual reality industry, which will help unify major hardware formats appearing on the market currently and accelerate the launch of relevant supporting content. In the White Paper released in April 2016, it is also clear that the lack of standards in industries is an important factor that hinders its development. In September 12, 2016, Notice of the General Office of the State Council on Printing and Distributing the Consumer Product Standard Enhancement Plan (2016-2020) also mentioned the promotion of standardization of innovative technologies such as artificial intelligence and virtual reality. In view of the lack of standards in the development of China's virtual reality industry currently, we should speed up the construction of China's virtual reality industry standard 
system, and increase investment in the standardization of virtual reality technology to support the large-scale application and development of the industry.

\section{Shortcomings and Prospects}

The current research is still limited. First of all, the keywords of the current research did not include all the related words of the virtual reality, and only included the categories of "virtual reality", "virtual reality system" and "virtual reality technology". Secondly, data we used was the number of patent applications, rather than the number of patent disclosure. Not only the number of patent had deviations, the quality of patents also had an impact. Finally, due to the lag time of 18 months from the filing date to the publication date and the collection and entry delay of the data in the patent database, the time lag exists. So that there may be some errors in the results. Further studied should be verified.

In the future, the prediction of the development trend of virtual reality technology may still be combined with other methods and tools, such as the activity index of different technology types and the patent portfolio analysis method, which can make the prediction of the result more accurate and reliable.

\section{Fund Project}

Guangdong Provincial Science and Technology Plan Project "Science and Technology Revolution and Technology Foresight Think Tank Construction" (No.2016B070702001).

Guangzhou City Humanities and Social Science Key Research Base Funded by Guangzhou City Large Enterprise Innovation System Construction Research Center.

\section{References}

[1] Lanier, J. (1992) Virtual Reality: The Promise of the Future. Interactive Learning International, 8, 275-279.

[2] Xia, M. (2017) Talking About the Virtual Reality Technology. Communication World, No. 02, 27-28.

[3] Xia, W.S. (2017) Research on the Development Situation and Trend of AR Mobile Game-Taking Pokemon Go Game as an Example. Journal of Communication University of China (Science and Technology), No. 3, 14-18.

[4] Slater, M. and Sanchez-Vives, M.V. (2016) Enhancing Our Lives with Immersive Virtual Reality. Frontiers in Robotics and AI, 3, Article 74. https://doi.org/10.3389/frobt.2016.00074

[5] Bastug, E., Bennis, M., Medard, M., et al. (2017) Toward Interconnected Virtual Reality: Opportunities, Challenges, and Enablers. IEEE Communications Magazine, 55, 110-117. https://doi.org/10.1109/MCOM.2017.1601089

[6] China Electronics News (2017) The Five Core Technologies of Virtual Reality Were Selected in the "Guidelines of Common Key Technologies for Industry Development. http://www.7tin.cn/news/100062.html

[7] Zhang, T., Yan, R.Y., Cui, S.N. and Tian, L. (2014) A Patentometric Analysis on Several Common Scientific Instruments in Field of Pharmaceutical Research. China 
Pharmaceuticals, 23, 12-15.

[8] Morar, M. and Agachi, P.S. (2010) Review: Important Contributions in Development and Improvement of the Heat Integration Techniques. Computers \& Chemical Engineering, 34, 1171-1179. https://doi.org/10.1016/j.compchemeng.2010.02.038

[9] Huang, L.C., Wang, K. and Wang, K.K. (2014) Technology Hot Spots and Fronts of Household Air Conditioner: Identification and Trend Analysis Based on CiteSpace. Journal of Intelligence, No. 2, 40-43.

[10] Ma, J.R. (2007) Core Technology and Core Competence: A Study of Combination of Industry, Teaching and Research Based on Enterprises. China High-Tech Enterprise, No. 13, 14-16.

[11] Chen, Y. (2014) Principles and Applications of Analyzing a Citation Space. Science Press,.

[12] Teng, Y.L. (2017) The Analysis of Hotspot and Detection of Research Front of Supply Chain Management Domestic and Abroad Based on Knowledge Map. Jilin University, Changchun.

[13] Xiao, W. and Zhang, S.Y. (2016) The Frontier, the Focus, and the Trend of Blended Learning Research-A Quantitative Research Using Citespace. Electronic Education Research, 37, 27-33+57.

[14] China Securities Network (2016) Virtual Reality Application Accelerates Expanding A-Share Market Opportunity Geometry. http://finance.ifeng.com/a/20161027/14966055_0.shtml

[15] Zhu, X.M. and Lan, L. (2016) The Development of Foreign Virtual Reality. Radio and Television Information, No. 04, 37-39. 